\title{
First-Wave COVID-19 Pandemic in Greece: The Role of Demographic, Social, and Geographical Factors in Life Satisfaction during Lockdown
}

\author{
Evgenia Anastasiou *(D) and Marie-Noelle Duquenne (D) \\ Department of Planning and Regional Development, University of Thessaly, 38334 Volos, Greece; mdyken@uth.gr \\ * Correspondence: evanastasiou@uth.gr
}

Citation: Anastasiou, Evgenia, and Marie-Noelle Duquenne. 2021. First-Wave COVID-19 Pandemic in Greece: The Role of Demographic, Social, and Geographical Factors in Life Satisfaction during Lockdown. Social Sciences 10: 186. https:// doi.org/10.3390/socsci10060186

Academic Editor: Nigel Parton

Received: 23 April 2021

Accepted: 18 May 2021

Published: 22 May 2021

Publisher's Note: MDPI stays neutral with regard to jurisdictional claims in published maps and institutional affiliations.

Copyright: (c) 2021 by the authors. Licensee MDPI, Basel, Switzerland. This article is an open access article distributed under the terms and conditions of the Creative Commons Attribution (CC BY) license (https:// creativecommons.org/licenses/by/ $4.0 /)$.

\begin{abstract}
The onset of the coronavirus pandemic led to profound changes in populations' everyday lives. The main purpose of this research is to investigate the factors that affected life satisfaction during the first-wave lockdown in Greece. A web-based survey was developed, and 4305 questionnaires were completed corresponding to all Greek regional units. Statistical modeling (multivariate logistic regression) was performed to evaluate to which extent significant geographical attributes and socioeconomic characteristics are likely to influence life satisfaction during lockdown due to the pandemic. In the course of the present work, some key findings emerged: social distancing and confinement measures affected mostly women in relation to men; there was a strong positive association between life satisfaction and age, especially as regards the older population; changes to employment status, increase in psychosomatic disorders, and increased usage of social media were also likely to negatively impact people's life satisfaction. By contrast, trust in the government and the media and limited health concerns seem to have a strong association with subjective wellbeing. Finally, life satisfaction does not depend much on geographical characteristics such as urbanity or insularity, highlighting that the lockdown had an impact on the Greek population regardless of the physical isolation.
\end{abstract}

Keywords: COVID-19; population; sociodemographic factors; life satisfaction; lockdown; multivariate logistic regression; Greece

\section{Introduction}

Since the beginning of the year 2020, COVID-19 has affected societies, economies, and individuals in every aspect. The increasing infection and mortality rate, substantial restrictions, prolonged lockdowns, and the economic downturn have negatively affected most people's mental health and wellbeing (Gavalas 2020).

During the first wave of the pandemic, Greece registered a significantly smaller virus outbreak compared to other European countries (Peto et al. 2020). Specifically, by the end of May 2020, 2917 confirmed cases had been reported, and 175 COVID-19-related deaths (National Public Health Organization 2020). The Greek government devised various strategies, such as social distancing and the suspension of economic activities, in an attempt to reduce and control the COVID-19 infection rate in the country. The Greek authorities implemented a total lockdown policy from mid-March 2020 to help to contain the pandemic at a relatively low level.

Due to these efforts, normal life changed, and the general population had to adapt to a new reality characterized by indefinite changes and unpredictable effects on multiple levels. Though the Greek population accepted the "Stay at home" edict, the feeling of life dissatisfaction and social isolation sharply increased, especially for people aged 25-34 years (Anastasiou and Duquenne 2020). The two months of lockdown affected the life satisfaction rate, while isolation in closed settings affected most individuals both physically and psychologically (White and Van Der Boor 2020). Beyond the direct effects on individual 
and collective health, the pandemic-due to the measures inevitably imposed by the governments-has caused significant collateral effects in terms of populations' wellbeing.

The main purpose of this research is to explore the determinants of life satisfaction during the first-wave pandemic in Greece. Based on the results of a web-based survey conducted during the period of April to May 2020, the objective of the present research is to explore to which extent main life satisfaction determinants-especially spatial, demographic, and social aspects-contributed to a deterioration in general life satisfaction in Greece during the first lockdown period. In order to better evaluate the life satisfaction of the Greek population during this lockdown, the research examined the impact of various aspects, such as employment situation, demographic status, psychosomatic disorders, sleep patterns, health concerns, social life, and trust in the government and media. The contribution of this study lies in exploring the factors determining life satisfaction under a sudden and pervasive crisis.

\section{Life Satisfaction during an Isolation Period}

For several decades, important literature on life satisfaction and subjective wellbeing has been produced in order to evaluate the quality of life from a personal perspective (Blanchflower and Oswald 2000; Diener et al. 2018; Oishi et al. 2018). More recently, a growing number of studies have focused more specifically on worsening mental health status and wellbeing during the isolation period (Brodeur et al. 2020; Davillas and Jones 2020). During the period of April/May 2020, life satisfaction in Europe was at moderate levels (mean $=6.3$ on a scale from 1 to 10) (Eurofound 2020) (Figure 1); young people and women were the demographic groups most impacted during the lockdown period. Having a paid job, living with a partner, and daily exercise contributing to maintaining good physical health were also considered to be major determinants of wellbeing, while restrictions on mobility, changes in workload, and decrease in income were associated with increased levels of anxiety and dissatisfaction (de Pedraza et al. 2020).

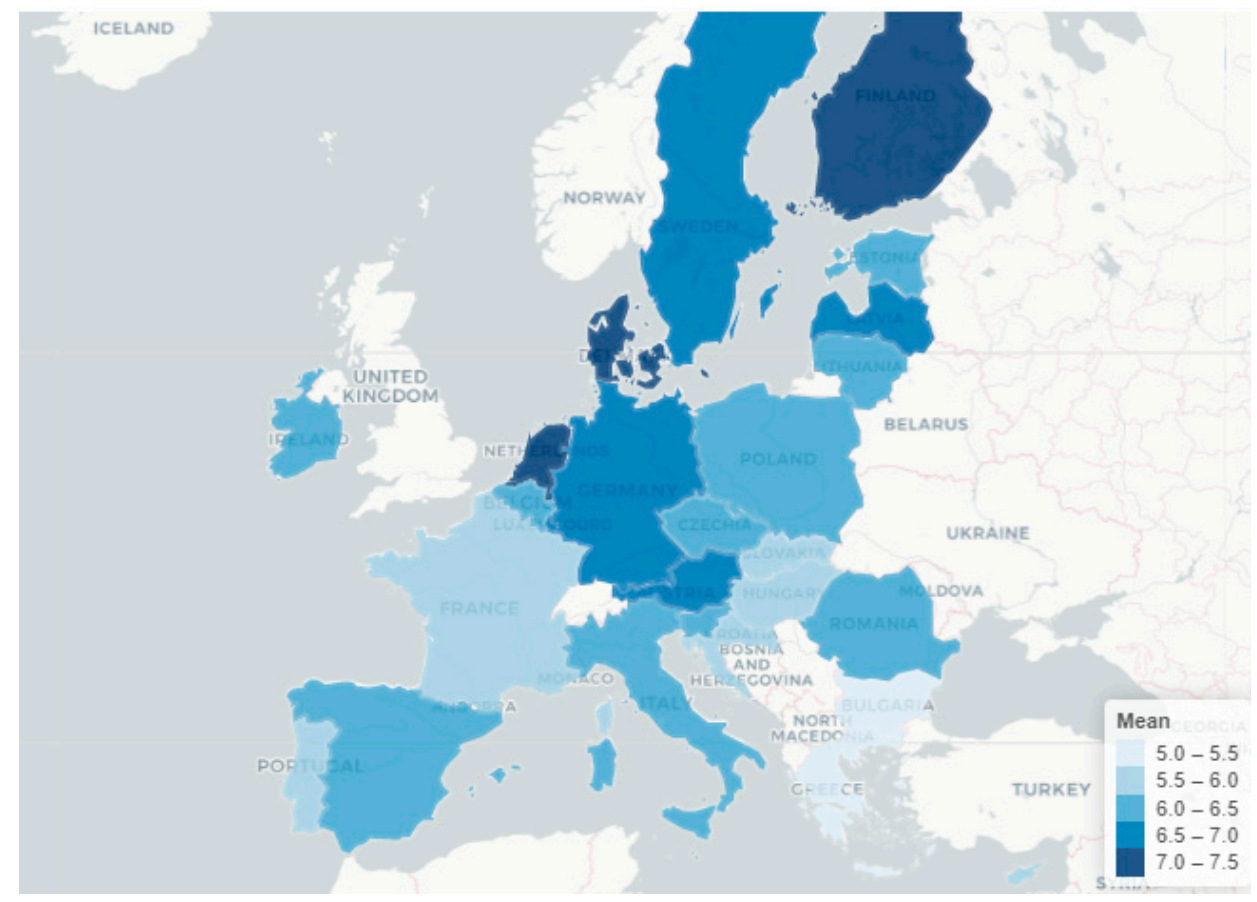

Figure 1. Life satisfaction in selected European countries during April/May 2020 (on a scale of 1-10).

An empirical question challenging the academic community is whether policy decisions to tackle the spread of the pandemic affect peoples' anxiety, subjective wellbeing, and life satisfaction (Tubadji et al. 2020). The confinement measures and quarantine imposed in Italy were in line with the country's infection curve (Xuefei 2020). The lateness of the inter- 
ventions regarding lockdown enforcement considerably impacted the Italian population's wellbeing, with significant disruptions in family life (Biroli et al. 2020). The UK's policy response to the pandemic and, consequently, lockdown were delayed. The UK, and especially England, experienced a significant reduction in life satisfaction and happiness during the national lockdown (UK Office for National Statistics 2020). On the other hand, Sweden opted against implementing a lockdown. A significant part of the Swedish population still presented depression symptoms (McCracken et al. 2020), but in general, the life satisfaction levels during April/May were among the highest in Europe (Independent SAGE 2020), demonstrating that strong democratic states deal with the pandemic with comparative advantages (Rambaree and Nässén 2020).

Restrictive measures were also widely perceived as a form of social isolation, leading to a degradation of individual life satisfaction and subjective wellbeing (Berg-Weger and Morley 2020; Brooks et al. 2020; Galea et al. 2020; Smith and Lim 2020; Smith et al. 2020). The measures necessarily imposed because of COVID-19 have affected a large part of the world's population, generating various types of stressors (Usher et al. 2020). In Greece, a relatively limited number of studies have been conducted.

Greece has opted for the implementation of severe isolation measures, generating a significant level of stress in the population, as observed in other countries with very strict measures (Chen et al. 2020a; Chen et al. 2020b; Dymecka et al. 2021; Polizzi et al. 2020). The Greek population complied with the social distancing measures; regardless, participants admitted to being affected socially and psychologically during the lockdown period (Anastasiou and Duquenne 2021). The feeling of social isolation was associated with unusual life patterns and adjustment to new lifestyle choices in regard to health, economy, socialization, and demographic status variations, among others.

Women and older adults (Parlapani et al. 2020a) and less educated individuals (Tsipropoulou et al. 2020) registered higher anxiety levels associated with pandemicrelated fear. Additionally, participants living alone presented higher levels of loneliness (Parlapani et al. 2020a). Psychological distress associated with isolation might lead to psychosomatic problems, dysfunctional family and individual coping strategies, and alcoholism (Giannopoulou and Tsobanoglou 2020). Financial hardships during confinement increased the risks of panic and mental disorders on the Greek population (Gavalas 2020), while they were also associated with family conflicts, domestic violence, and alcoholism, among others (Routen et al. 2020).

Considering the above first contributions as regards the impacts of the first lockdown period in Greece on subjective wellbeing, the aim of the present study is to focus more particularly on the role of demographic, social, and geographical factors on Greek personal life satisfaction during this recent period. As aforementioned, though a relatively limited number of research studies addressing issues such as psychological distress and mental health due to the pandemic have been conducted in Greece, the potential impacts of the geographical dimension on subjective wellbeing have still not been addressed. It is widely recognized that loneliness (subjective feeling) and social isolation (a more objective state) worsened during the pandemic (Zixin and Wang 2020). In this context, a question can be raised: To what extent could geographic isolation also reinforce the risk of feeling dissatisfied?

\section{Data and Econometric Methodology}

\subsection{Data and Sampling}

To accomplish the aims of the present study, a web-based survey was conducted on the Greek population during the lockdown period (March to May 2020) imposed by COVID19 in Greece. The measurement instrument, which is a self-administered questionnaire, consists of four sections: (a) demographic characteristics of the population (10 questions), (b) characteristics of the respondents' psychosomatic situation (10 questions), (c) changes in everyday life before and during lockdown (23 questions), and (d) perceptions regarding COVID-19-related social and economic developments (16 questions). Due to the restrictions 
on population mobility, the survey was conducted online by sharing the questionnaire on social media networks (Facebook, Twitter, LinkedIn) and on cultural, leisure, and sport associations. Informed consent was obtained from all participants, and data were collected anonymously.

The reference population regards the population of Greece aged 15-65 years. This represents $63.6 \%$ of the country's total population (ELSTAT 2014). Data were collected from individuals aged 15 to 65 years, while the sampling covered all regions of Greece (urban, rural areas, mountainous zones, and islands). As regards potential young respondents under 18 years old, the questionnaire included a preliminary field to be completed in order to explicitly require parental approval. A total of 4216 questionnaires were completed, corresponding to a $99 \%$ CI and margin of error of about $2 \%$, in line with the demographic structure of the reference population. People over 65 years old were excluded from analysis, considering that it was considered to be difficult to obtain satisfactory representativeness since relatively few of them use the Internet. It is estimated ${ }^{1}$ that only $38 \%$ of the population aged 65-74 years are familiar with the Internet, compared to $99 \%$ among the youngest (18-34).

\subsection{Variables Selection and Presumed Effects}

Considering the determinants of life satisfaction during lockdown, an immediate question arises: Is it possible to detect different patterns between moderately satisfied and highly satisfied citizens in relation to those who are dissatisfied? Consequently, the dependent variable expresses Life satisfaction during lockdown (SatDLock) as perceived by the respondents. This variable is a categorical one measured on a three-point Likert scale; $1=$ Not Satisfied, 2 = Moderately Satisfied, 3 = Satisfied.

As regards the explanatory variables, the first group of parameters concerns the demographic, social, and geographical components (See Appendix A, Table A1). The selection of variables and their expected effect on life satisfaction was based on a systematic literature review as presented below.

The first interpretative variables are the classic demographics of gender and age. Gender was treated as a dichotomous variable taking values 0 for males and 1 for females, while age was classified into five big groups. In most empirical studies, the contribution of gender to life satisfaction appears to be significant (Audette et al. 2019; Della Giusta et al. 2011; Joshanloo and Jovanović 2020). Moreover, in times of COVID-19, it seems that women are more likely than men to report worse mental health (Moyser 2020) and, consequently, life satisfaction.

As regards the age variable, the younger generation, i.e., those aged 35 years and below, seemed to report more sensitiveness to social distancing (Glowacz and Schmits 2020), having been made lonelier and sadder by the lockdown (Sakka et al. 2020). On the other hand, prolonged loneliness for older adults is commonly associated with mental disorders such as depression (Frogoudaki et al. 2020). One's age, therefore, is more likely to increase pressure on life satisfaction, especially concerning young people aged under 35 years and the elderly.

The respondents' place of residence was classified into two categorical variables, urbanity and insularity. Settlements inhabited by more than 2000 inhabitants were considered to be urban, and settlements with up to 2000 inhabitants were rural, in accordance with Hellenic Statistical Authority definitions (ELSTAT 2020). The classification regarding insularity was built on the basis of whether an individual resides in a spatial unit in mainland Greece or on an island. These two variables allow taking into consideration the role of geographical proximity, referring to "physical distancing" (Torre 2020). Geographical distancing is often expected to generate more detrimental effects on people's life satisfaction (OECD/European Commission 2020), but the pandemic seems to have modified this situation. with rural inhabitants more likely to feel happiness comparatively to urban populations (CSO_Central Statistics Office 2020). Few studies have explored the wellbeing of islanders during the confinement measures. From the Island Global Research (2020) 
results, it is possible to infer that islanders have presented higher levels of wellbeing and optimism during the pandemic. Apart from the abovementioned categorical variables, the model also introduces seven interpretative variables that were extracted through principal component analysis (PCA) on the basis of 22 initial items related to the respondents' evaluation as regards their psychosomatic situation, their attitudes, and behavior during the confinement, as well as their general perception of the situation. Afterward, the values of the seven extracted principal components were transformed into a scale ranging from 0 to 100 (Anastasiou and Duquenne 2020). More precisely, these interpretive variables concern (i) the psychosomatic situation, which is the level of somatic misfunctioning due to stress posed by COVID-19; (ii) the employment situation, which monitors individuals' current employment status based on working hours, employment type, job position, and teleworking; (iii) changes in sleep patterns during the confinement, i.e., shifts in sleep and bedtime schedule, a behavior often observed during the pandemic (Cellini et al. 2020; Marelli et al. 2020; Parlapani et al. 2020b); (iv) socialization on the Internet, which is the level of Internet usage in order to communicate with friends. Maintaining communication through social platforms is obviously a strategy which was adopted by a large part of the population as the only avenue (Deepa 2020; Sakka et al. 2020); (v) family situation, which is a relative measurement of the family size, considering the existence of a marriage and children; (vi) health concern, which the level of worry about contracting COVID-19; and (vii) trust in the government and the media, which is the level to which people agree with the government's response to COVID-19 and their perception of news credibility.

\subsection{Econometric Model and Model Specification}

The present analysis attempts to investigate the likelihood of the Greek population being satisfied with life during the lockdown period imposed by COVID-19. A multinomial logistic regression analysis was implemented to explore the association between the independent and the interpretative variables. The econometric model is based on cross-sectional data as it studies a sample of 4305 individuals during the period of confinement measures. The general model is as follows:

$$
\begin{array}{r}
\operatorname{prob}(Y=j)=\exp \left(a_{0 j}+\beta_{1 j} X_{1}+\ldots+\beta_{n j} X_{n} / \sum_{i=1}^{m} \exp \left(a+\beta_{1 i} X_{1}+\ldots+\beta_{n j} X_{n}\right)\right. \\
\ln \left[\frac{\operatorname{prob}_{(i)}}{\operatorname{prob}_{(j)}}\right]=a_{0 i}+\beta_{1 i} X_{1}+\ldots+\beta_{n i} X_{n}+\varepsilon_{i}
\end{array}
$$

For the purposes of the present study, a logit for the time period was estimated, to capture the changing contribution of the geographical, demographic, and social determinants. In particular:

$$
\begin{aligned}
& \operatorname{prob}(Y=\text { SatDlock })=a_{0}+\beta_{1} S E X+\beta_{2} A G E+\beta_{3} U R B+\beta_{4} I N S+\beta_{5} F A M+\beta_{6} P S Y+\beta_{7} E M P+ \\
& \beta_{8} S O C+\beta_{9} H E A L+\beta_{10} S L E E+\beta_{11} G O V+\varepsilon
\end{aligned}
$$

where $\operatorname{prob}(Y=$ SatDlock $)$ presents the odds of the probability that an individual was moderately satisfied or highly satisfied rather than dissatisfied with life during the lockdown period. Consequently, the reference category in the model is " 1 = Not satisfied with life", and $\varepsilon$ stands for the disturbance term.

\section{Results}

The sample consists of 4305 valid questionnaires, $70 \%$ completed by women and 30\% by men (Table 1). This unfortunately unbalanced sample is partly due to the data collection method (web-based survey), but it may also suggest that, during the confinement, women were more likely to participate in the survey than men, as has been quite often observed in sociological surveys (Curtin et al. 2000; Moore and Tarnai 2002; Singer et al. 2000). It is also 
not surprising that the elderly (65 years and over) are under-represented due to the fact that few of them, especially in Greece, use the Internet and/or a computer (Alexandrakis 2017).

Table 1. Descriptive statistics of categorical variables.

\begin{tabular}{|c|c|c|c|c|c|c|}
\hline \multirow{2}{*}{\multicolumn{2}{|c|}{ Covariates }} & \multirow{2}{*}{ Overall N (\%) } & \multicolumn{4}{|c|}{ Life Satisfaction during Lockdown } \\
\hline & & & None & Moderate & High & $p$-Value \\
\hline \multicolumn{2}{|c|}{ Overall N (\%) } & $4256(100)$ & $1551(36.4)$ & $1518(35.7)$ & 1187(27.9) & \\
\hline \multirow{2}{*}{ Gender } & Male & $1249(29.0)$ & $493(39.5)$ & $428(34.3)$ & $328(26.3)$ & \multirow{2}{*}{0.029} \\
\hline & Female & $3056(71.0)$ & $1076(35.2)$ & $1106(36.2)$ & $874(28.6)$ & \\
\hline \multirow[t]{5}{*}{ Age } & $17-24$ & $722(17.0)$ & $284(39.3)$ & $250(34.6)$ & $188(26.0)$ & \multirow{5}{*}{0.002} \\
\hline & $25-39$ & $1954(45.9)$ & $720(36.8)$ & $720(36.8)$ & $514(26.3)$ & \\
\hline & $40-54$ & $1167(27.4)$ & $406(34.8)$ & $409(35.0)$ & $352(30.2)$ & \\
\hline & $55-64$ & $347(8.2)$ & $131(37.8)$ & $111(32.0)$ & $105(30.3)$ & \\
\hline & $>65$ & $66(1.6)$ & $10(15.2)$ & $28(42.4)$ & $28(42.4)$ & \\
\hline \multirow{2}{*}{ Urbanity } & Urban & 3957 (93.9) & 1450 (36.6) & 1403 (35.5) & 1104 (27.9) & \multirow{2}{*}{0.607} \\
\hline & Rural & 259 (6.1) & 88 (34.0) & 99 (38.2) & $72(27.8)$ & \\
\hline \multirow{2}{*}{ Insularity } & Mainland & 3739 (88.7) & $1350(36.1)$ & 1342 (35.9) & 1047 (28.0) & \multirow{2}{*}{0.357} \\
\hline & Island & 477 (11.3) & 188 (39.4) & $160(33.5)$ & $129(27.0)$ & \\
\hline
\end{tabular}

As regards life satisfaction during lockdown, more than one-third of respondents declared not being satisfied, while almost $30 \%$ reported being highly satisfied. Gender and age structure are statistically significant among life satisfaction outcomes $(p<0.05)$. A total of $88(34.0 \%)$ people residing in rural areas and $188(39.4 \%)$ in islands declared being dissatisfied with life during lockdown. Finally, contrarily to what has been assumed, $\chi^{2}$ tests do not suggest a statistically significant relationship between urbanity $(p>0.05)$ or insularity $(p>0.05)$ and life satisfaction levels.

Two regression models were applied (Appendix A: Tables A2 and A3) to evaluate the impact of geographical, demographic, and social parameters on the risk of feeling dissatisfied with life during lockdown in Greece. The results depict considerable alterations in the significance levels of specific variables. More specifically, urbanity, insularity, family size, and changes in sleep patterns are not significantly predictive $(p>0.05)$. The model presented (Table 2) contributes to evaluating the statistically significant predictors during the lockdown period on satisfaction with life.

Table 2. Multinomial logistic regression models predicting satisfaction with life during lockdown, based on demographic and social factors.

\begin{tabular}{|c|c|c|c|c|c|c|}
\hline \multirow[t]{2}{*}{ Not Satisfied with Life (Ref.) } & \multicolumn{3}{|c|}{ Moderate Satisfaction } & \multicolumn{3}{|c|}{ High Satisfaction } \\
\hline & OR & $p$-Value & $95 \% \mathrm{CI}$ & OR & $p$-Value & $95 \%$ CI \\
\hline Intercept & & 0.014 & & & 0.125 & \\
\hline Gender & & & & & & \\
\hline Male & 0.63 & 0.000 & $0.529-0.750$ & 0.449 & 0.000 & $0.368-0.549$ \\
\hline \multicolumn{7}{|l|}{ Female (Ref.) } \\
\hline \multicolumn{7}{|l|}{ Age } \\
\hline $15-24$ & 0.573 & 0.169 & $0.258-1.268$ & 0.613 & 0.251 & $0.266-1.414$ \\
\hline $25-39$ & 0.539 & 0.117 & $0.249-1.167$ & 0.517 & 0.110 & $0.231-1.160$ \\
\hline $40-54$ & 0.439 & 0.037 & $0.203-0.952$ & 0.433 & 0.043 & $0.193-0.973$ \\
\hline $55-64$ & 0.338 & 0.008 & $0.152-0.751$ & 0.332 & 0.010 & $0.144-0.768$ \\
\hline$>65($ Ref. $)$ & & & & & & \\
\hline Psychosomatic situation & 0.569 & 0.000 & $0.523-0.618$ & 0.340 & 0.000 & $0.309-0.375$ \\
\hline Employment situation & 0.815 & 0.000 & $0.748-0.887$ & 0.747 & 0.000 & $0.678-0.824$ \\
\hline Socialization on the Internet & 0.885 & 0.002 & $0.820-0.954$ & 0.871 & 0.001 & $0.799-0.948$ \\
\hline Health concern & 1.526 & 0.000 & $1.413-1.647$ & 2.085 & 0.000 & $1.905-2.282$ \\
\hline Trust in the government and the media & 1.292 & 0.000 & $1.195-1.398$ & 1.479 & 0.000 & $1.349-1.623$ \\
\hline
\end{tabular}


The likelihood ratio statistics are highly significant $\left(\chi^{2}=947.612 ; p<0.000\right)$, $($ AIC $=8388.923)$, suggesting a good model fit. The percentage of well-predicted classification $(50 \%)$ is higher than the proportional by chance accuracy rate $(42.2 \%)$, confirming the strong explanatory power of the model.

A first insight is extracted, interpreting the regression analysis results; the predictors in moderate satisfaction feeling become more intense in the case of high satisfaction. As regards gender, women have $1.59(\mathrm{OR}=0.630, p<0.001)$ and 2.9 times $(\mathrm{OR}=0.449$, $p<0.001$ ) higher odds of feeling moderately and highly satisfied, respectively, compared to men. The age structure also plays an important role, especially in ages greater than 40 years. Individuals aged 65 years and over (generally retirees) have an increased chance of feeling very satisfied with life in relation to those aged 40-54 $(\mathrm{OR}=0.433, p<0.05)$ and 55-64 $(\mathrm{OR}=0.332, p=0.001)$. This finding may be due to the increased anxiety of middle-aged people regarding responding to social and/or economic requirements. The fact that many of them were, during the lockdown period, in precarious employment conditions makes them logically more vulnerable than retirees.

The feeling of dissatisfaction during lockdown rather than moderate or high satisfaction increased by $43 \%(\mathrm{OR}=0.569,95 \% \mathrm{CI}$ : $0.523-0.618)$ and $66 \%(\mathrm{OR}=0.34 ; 95 \% \mathrm{CI}$ : 0.309-0.375), respectively, for each increase of one unit in the psychosomatic situation. In other words, citizens who considered themselves to be in a sensitive position regarding their psychosomatic situation were much more likely to suffer as a result of measures that enhance social isolation. This means that the pandemic can eventually cause additional forms of health problems. Furthermore, the employment situation scale is negatively associated with satisfaction levels. A change in working hours or employment status reduces life satisfaction by $25 \%(\mathrm{OR}=0.871 ; 95 \% \mathrm{CI}$ : $0.799-0.948)$. The uncertainty in terms of employment generated by the restrictive measures on economic activity clearly increases (in non-negligible proportions) the feeling of dissatisfaction. Finally, dissatisfaction seems to be associated with an increase in socialization on the Internet, in relation both to moderate $(\mathrm{OR}=0.885 ; 95 \% \mathrm{CI}: 0.820-0.954)$ and high levels of life satisfaction (OR $=0.747$; 95\% CI: 0.678-0.824). The expected negative impact of social media on people's subjective wellbeing highlights the need to be connected with those appearing happy and satisfied with their lives.

Health concern was statistically significantly associated with reporting higher levels of life satisfaction $(\mathrm{OR}=2.085 ; 95 \% \mathrm{CI}$ : 1.905-2.282 for a 1-unit increase on the health concern scale), meaning that individuals worried about them or their loved ones becoming infected feel dissatisfied with life. Higher trust levels in the government and the media were also associated with higher satisfaction with life $(\mathrm{OR}=2.085 ; 95 \% \mathrm{CI}$ : 1.905-2.282). This particular finding is of major importance as it addresses the tolerance levels toward the policies implemented to combat the effects of the pandemic.

The findings of the analysis are consistent with those of previous studies. Happiness during one's lifespan follows a U-shaped trend, reflecting greater satisfaction among the elderly rather than middle-aged people (Frey and Stutzer 2002; Kutubaeva 2019). Women report higher life satisfaction than men, as shown by studies not taking into consideration emergency situations such as COVID-19 (Joshanloo and Jovanović 2020). Social media use, despite the apparent advantage of socialization, is negatively associated with life satisfaction (Stieger 2019). Likewise, both the mental health of the population and the instability of employment status affected by the COVID-19 outbreak have also led to life dissatisfaction (de Pedraza et al. 2020). Finally, trust in the government and the media, in line with previous research conducted in Greece (Georgakopoulos 2020), enhances life satisfaction.

\section{Discussion and Conclusions}

The confinement measures implemented by the Greek government in March 2020 played an essential role in reducing infections and controlling the COVID-19 response across the nation (Zixin and Wang 2020). However, this move had massive consequences 
on the wellbeing and lives of the population across the country. The present study provides substantial information on the determinants of life satisfaction during lockdown.

One of the primary factors that affected the Greek population during the pandemic is their demographic characteristics. Women seem to be more vulnerable than men in terms of satisfaction. This finding is in line with recent bibliography presenting women as confronted with negative emotions and psychological distress in times of COVID-19 (Vatavali et al. 2020). As regards the contribution of age, it appears that older adults, aged 65 years and over, are more satisfied with life during lockdown in relation to the 40-54- and 55-64-year-old groups, whereas no statistically significant findings were identified for the younger age groups. This appraisal was confirmed by the existing literature. The elderly are not very vulnerable to the COVID-19 pandemic in terms of life satisfaction (Kivi et al. 2021), and they rate their life satisfaction and wellbeing as being higher than those of younger and middle-aged people (Bidzan-Bluma et al. 2020; de Pedraza et al. 2020).

People faced psychosocial challenges associated with their adapted living styles during the isolation period. The most common challenges amongst Greeks included psychological and psychosomatic disorders, employment situations, and social media use.

Media outlets were the primary sources of information for the majority of the Greek population and essential determiners of people's life satisfaction. Considering that this is the first pandemic-related emergency in Greece, Greek institutions adopted measures to protect people's lives. The measures taken to tackle the spread of the pandemic were effective since Greece was doing relatively well compared to other European countries, and this outcome was reflected in the population's trust. This supports the findings of previous studies that found that government interventions influence life satisfaction levels (Wu et al. 2021).

Interestingly, changes in everyday sleep patterns do not seem to have had a significant effect on the subjective wellbeing of the Greek population. Previous studies demonstrated that changes in sleep quality impact life satisfaction (Pilcher et al. 1997). Changes in daily sleep-wake patterns during COVID-19 also proved to cause negative emotions (Dai et al. 2021). Furthermore, geographic differences were not found to have a statistically significant effect on life satisfaction during lockdown, either concerning urbanity or insularity.

Overall, the potential positive impacts of a mandatory mass lockdown must be carefully weighed in relation to the possible psychological costs. The Greek government's response to the first wave of the pandemic was effective, reducing the number of cases. In terms of satisfaction, however, concerns emerge about the tolerance levels of the population pending a next phase of the pandemic.

The above results should be considered to achieve a better management of such crises, thus contributing to achieving higher life satisfaction and subjective wellbeing. The implications could contribute to an evaluation of interventions as regards preventing and/or addressing the feeling of social isolation imposed by COVID-19.

The present study, however, comes with a caveat. As this research was conducted during the very early stage of the pandemic, it was possible to capture the reaction of the Greek population to a sudden and horizontal effect. Updated research data are needed in order to examine and understand life satisfaction trend in the next waves of the pandemic, taking into account the burden of psychological fatigue from continuous confinement and the significant increase in confirmed cases and COVID-19-related deaths. In future studies, the relationship between life satisfaction and a broad range of health factors and other COVID-related factors, such as physical contact with COVID-19 cases, cases in the place of residence, and quarantine in the place of residence, should be explored.

Author Contributions: Conceptualization, E.A. and M.-N.D.; methodology, E.A. and M.-N.D.; software, E.A. and M.-N.D.; validation, E.A. and M.-N.D.; formal analysis, E.A. and M.-N.D.; investigation, E.A. and M.-N.D.; resources, E.A. and M.-N.D.; data curation, E.A. and M.-N.D.; writingoriginal draft preparation, E.A. and M.-N.D.; writing-review and editing, E.A. and M.-N.D.; visualization, E.A. and M.-N.D. supervision, E.A. and M.-N.D.; project administration, E.A. and M.-N.D.; 
funding acquisition, E.A. and M.-N.D. All authors have read and agreed to the published version of the manuscript.

Funding: This research received no external funding.

Institutional Review Board Statement: Not applicable.

Informed Consent Statement: Not applicable.

Data Availability Statement: The data presented in this study are available on request from the corresponding author. The data are not publicly available due to confidentiality agreements with participants.

Conflicts of Interest: The authors declare no conflict of interest.

\section{Appendix A}

Table A1. Interpretative variables.

\begin{tabular}{|c|c|c|c|}
\hline Explanatory Variables & Label & Description & Data Sources \\
\hline Gender & SEX & $\begin{array}{c}0=\text { Male } \\
1=\text { Female } \\
1=15-24\end{array}$ & Own field research \\
\hline Age & AGE & $\begin{array}{c}2=25-39 \\
3=40-54 \\
4=55-64 \\
5=\text { over } 65\end{array}$ & Own field research \\
\hline Urbanity & URB & $\begin{array}{c}0=\text { Urban } \\
1=\text { Rural }\end{array}$ & Own calculations \\
\hline Insularity & INS & $\begin{array}{c}0=\text { Mainland } \\
1 \text { = Island }\end{array}$ & Own calculations \\
\hline Family size & FAM & Scale [0-100] & (Anastasiou and Duquenne 2021) \\
\hline Psychosomatic situation & PSY & Scale $[0-100]$ & (Anastasiou and Duquenne 2021) \\
\hline Employment situation & EMP & Scale [0-100] & (Anastasiou and Duquenne 2021) \\
\hline Socialization on the Internet & $\mathrm{SOC}$ & Scale [0-100] & (Anastasiou and Duquenne 2021) \\
\hline Health concern & HEAL & Scale [0-100] & (Anastasiou and Duquenne 2021) \\
\hline Changes in sleep patterns & SLEE & Scale [0-100] & (Anastasiou and Duquenne 2021) \\
\hline Trust in the government and the media & GOV & Scale $[0-100]$ & (Anastasiou and Duquenne 2021) \\
\hline
\end{tabular}

Table A2. Life satisfaction during and before lockdown, likelihood ratio tests-accepted model.

\begin{tabular}{|c|c|c|c|c|c|c|}
\hline \multirow[b]{2}{*}{ Effect } & \multicolumn{3}{|c|}{ Model Fitting Criteria } & \multicolumn{3}{|c|}{ Likelihood Ratio Tests } \\
\hline & $\begin{array}{c}\text { AIC of Reduced } \\
\text { Model }\end{array}$ & $\begin{array}{c}\text { BIC of Reduced } \\
\text { Model }\end{array}$ & $\begin{array}{l}-2 \text { Log Likelihood } \\
\text { of Reduced Model }\end{array}$ & Chi-Square & df & Sig. \\
\hline Intercept & 8388.923 & 8528.757 & $8344.923^{a}$ & 0.000 & 0 & \\
\hline Psychosomatic situation & 8943.944 & 9071.065 & 8903.944 & 559.020 & 2 & 0.000 \\
\hline Employment situations & 8423.446 & 8550.567 & 8383.446 & 38.522 & 2 & 0.000 \\
\hline Socialization on the Internet & 8398.137 & 8525.259 & 8358.137 & 13.214 & 2 & 0.001 \\
\hline Health concern & 8673.631 & 8800.753 & 8633.631 & 288.708 & 2 & 0.000 \\
\hline $\begin{array}{c}\text { Trust in the government and } \\
\text { the media }\end{array}$ & 8463.321 & 8590.443 & 8423.321 & 78.397 & 2 & 0.000 \\
\hline Sex & 8449.743 & 8576.865 & 8409.743 & 64.820 & 2 & 0.000 \\
\hline Age & 8393.929 & 8482.914 & 8365.929 & 21.006 & 8 & 0.007 \\
\hline
\end{tabular}

The chi-square statistic is the difference in 2-log likelihoods between the final model and a reduced model. The reduced model is formed by omitting an effect from the final model. The null hypothesis is that all parameters of that effect are $0 .{ }^{\text {a }}$ This reduced model is equivalent to the final model because omitting the effect does not increase the degrees of freedom. 
Table A3. Life satisfaction during lockdown, likelihood ratio tests—rejected model.

\begin{tabular}{|c|c|c|c|c|c|c|}
\hline \multirow[b]{2}{*}{ Effect } & \multicolumn{3}{|c|}{ Model Fitting Criteria } & \multicolumn{3}{|c|}{ Likelihood Ratio Tests } \\
\hline & $\begin{array}{l}\text { AIC of Reduced } \\
\text { Model }\end{array}$ & $\begin{array}{c}\text { BIC of Reduced } \\
\text { Model }\end{array}$ & $\begin{array}{l}-2 \text { Log Likelihood } \\
\text { of Reduced Model }\end{array}$ & Chi-Square & df & Sig. \\
\hline Intercept & 8228.689 & 8418.774 & $8168.689^{a}$ & 0.000 & 0 & \\
\hline Psychosomatic situation & 8760.938 & 8938.350 & 8704.938 & 536.249 & 2 & 0.000 \\
\hline Employment situations & 8255.174 & 8432.586 & 8199.174 & 30.484 & 2 & 0.000 \\
\hline Socialization on the Internet & 8234.700 & 8412.112 & 8178.700 & 10.010 & 2 & 0.007 \\
\hline Health concern & 8509.838 & 8687.250 & 8453.838 & 285.149 & 2 & 0.000 \\
\hline $\begin{array}{c}\text { Trust in the government and } \\
\text { the media }\end{array}$ & 8286.398 & 8463.811 & 8230.398 & 61.709 & 2 & 0.000 \\
\hline Changes in sleep patterns & 8224.951 & 8402.363 & 8168.951 & 0.261 & 2 & 0.878 \\
\hline Marital Status & 8226.728 & 8404.140 & 8170.728 & 2.038 & 2 & 0.361 \\
\hline Urbanity & 8225.296 & 8402.708 & 8169.296 & 0.606 & 2 & 0.738 \\
\hline Insularity & 8226.087 & 8403.500 & 8170.087 & 1.398 & 2 & 0.497 \\
\hline Sex & 8289.761 & 8467.173 & 8233.761 & 65.072 & 2 & 0.000 \\
\hline Age & 8224.272 & 8363.668 & 8180.272 & 11.583 & 8 & 0.171 \\
\hline
\end{tabular}

The chi-square statistic is the difference in 2-log likelihoods between the final model and a reduced model. The reduced model is formed by omitting an effect from the final model. The null hypothesis is that all parameters of that effect are $0 .{ }^{\text {a }}$ This reduced model is equivalent to the final model because omitting the effect does not increase the degrees of freedom.

\section{Note}

1 Available online: https://www.businessmentor.gr/statistika-xrisis-internet-stin-ellada/ (accessed on 15 March 2021). Business Mentor, 2018 Internet Usage Statistics in Greece.

\section{References}

Alexandrakis, Diogenis. 2017. The use of computers and Internet by older people and their intention to participate to ICT training programs. Greek Review of Educational-Scientific Issues 12: 64-77. (In Greek)

Anastasiou, Evgenia, and Marie-Noelle Duquenne. 2020. Coronavirus in Society: The Geography of Social Distancing Measures in Greece. Demo News 41.

Anastasiou, Evgenia, and Marie-Noelle Duquenne. 2021. What about the "Social Aspect of COVID"? Exploring the Determinants of Social Isolation on the Greek Population during the COVID-19 Lockdown. Social Sciences 10: 27. [CrossRef]

Audette, Andre, Sean Lam, Haley O'Connor, and Benjamin Radcliff. 2019. (E)Quality of Life: A Cross-National Analysis of the Effect of Gender Equality on Life Satisfaction. Journal of Happiness Studies 20: 2173-88. [CrossRef]

Berg-Weger, Marla, and John Morley. 2020. Loneliness and social isolation in older adults during the COVID-19 pandemic: Implications for gerontological social work. The Journal of Nutrition, Health and Aging 24: 456-58. [CrossRef]

Bidzan-Bluma, Ilona, Monika Bidzan, Pawel Jurek, Leszek Bidzan, Jessica Knietzsch, M. Stueck, and M. Bidzan. 2020. A Polish and German Population Study of Quality of Life, Well-Being, and Life Satisfaction in Older Adults During the COVID-19 Pandemic. Frontiers in Psychiatry 11: 1188. [CrossRef] [PubMed]

Biroli, Pietro, Steven Bosworth, Marina Della Giusta, AmaliaDi Girolamo, S. Jaworska, and J. Vollen. 2020. Family Life in Lockdown. IZA Discussion Paper No. 13398. Bonn: Institute of Labor Economics.

Blanchflower, David, and Andrew Oswald. 2000. Well-Being Over Time in Britain and the USA. Journal of Public Economics 88: 1359-86. [CrossRef]

Brodeur, Aabel, David Gray, Anik Islam, and Suraiya Jabeen Bhuiyan. 2020. A Literature Review of the Economics of COVID-19. No. 13411, Discussion Paper Series. Available online: www.iza.org (accessed on 18 January 2021).

Brooks, Samantha, Rebecca Webster, Louise Smith, Lisa Woodland, Simon Wesseley, Neil Greenberg, and G. Rubin. 2020. The psychological impact of quarantine and how to reduce it: Rapid review of the evidence. Lancet 395: 912-20. [CrossRef]

Cellini, Nicolla, Natale Canale, Giovanna Mioni, and Sebastiano Costa. 2020. Changes in sleep pattern, sense of time and digital media use during COVID-19 lockdown in Italy. Journal of Sleep Research 29: 1-5. [CrossRef] [PubMed]

Chen, Qiang, Chen Min, Wei Zhang, Ge Wang, Xiaoyue Ma, and Richard Evans. 2020a. Unpacking the black box: How to promote citizen engagement through government social media during the COVID-19 crisis. Computers in Human Behavior 110: 106380. [CrossRef]

Chen, Qiongni, Mining Liang, Yamin Li, Jincai Guo, Dongxue Fei, Ling Wang, Li He, Caihua Sheng, Yiwen Cai, Xiaojuan Li, and et al. 2020b. Mental health care for medical staff in China during the COVID-19 outbreak. The Lancet Psychiatry 7: E15-E16. [CrossRef]

CSO_Central Statistics Office. 2020. Social Impact of COVID-19 Survey April 2020—Well-Being. Available online: https:/ /www.cso. $\mathrm{ie} / \mathrm{en} /$ releasesandpublications/ep/p-sic19/socialimpactofcovid-19surveyapril2020/well-being/ (accessed on 1 April 2021). 
Curtin, Richard, Stanley Presser, and Eleanor Singer. 2000. The effects of response rate changes on the index of consumer sentiment. In Public Opinion Quarterly 64: 413-28. [CrossRef]

Dai, Wenjuan, Jieying Zhou, Guangming Li, Bin Zhang, and N. Ma. 2021. Maintaining normal sleep patterns, lifestyles and emotion during the COVID-19 pandemic: The stabilizing effect of daytime napping. Journal of Sleep Research, e13259. [CrossRef] [PubMed]

Davillas, Apostolos, and Andrew Jones. 2020. The COVID-19 Pandemic and Its Impact on Inequality of Opportunity in Psychological Distress in the UK. No. 2020-07, ISER Working Paper. Essex: Institute for Social and Economic Research, Available online: https:/ / econpapers.repec.org/RePEc:ese:iserwp:2020-07 (accessed on 25 January 2021).

de Pedraza, Pablo, Martin Guzi, and Kea Tijdens. 2020. Life Dissatisfaction and Anxiety in COVID-19 Pandemic, EUR 30243 EN. Luxembourg: Publications Office of the European Union. [CrossRef]

Deepa, Raj. 2020. Life Satisfaction during COVID-19. Journal of Human Ecology 71: 1-3. [CrossRef]

Della Giusta, Marina, Sarah Louise Jewell, and U. S. Kambhampati. 2011. Gender and Life Satisfaction in the UK. Feminist Economics 17: 1-34. [CrossRef]

Diener, Ed, Shigehiro Oishi, and L. Tay. 2018. Advances in subjective well-being research. Nature Human Behaviour 2: 253-60. [CrossRef]

Dymecka, Joanna, Rafal Gerymski, and Anna Machnik-Czerwik. 2021. How does stress affect our life satisfaction during COVID-19 pandemic? Moderating mediation analysis of sense of coherence and fear of coronavirus. Psychology, Health and Medicine. [CrossRef] [PubMed]

ELSTAT. 2014. Demographic and Social Characteristics of the Resident Population of Greece According to the 2011 PopulationHousing Census Revision of 20/3/2014. Available online: https:/ /www.statistics.gr/en/2011-census-pop-hous (accessed on 9 March 2021).

ELSTAT. 2020. Employment Status and Unemployment Rate, Workforce (Monthly)/June 2020. Available online: https://www. statistics.gr/el/statistics/- / publication/SJO02/ (accessed on 9 March 2021).

Eurofound. 2020. Living, Working and COVID-19 Dataset. Available online: https://www.eurofound.europa.eu/data/covid-19 / quality-of-life (accessed on 9 March 2021).

Frey, Bruno, and Alois Stutzer, eds. 2002. Happiness and Economics. Princeton: Princeton University Press, Available online: https: // press.princeton.edu/books/paperback/9780691069982/happiness-and-economics (accessed on 15 March 2021).

Frogoudaki, Alexandra, Dimitrios Farmakis, Dimitrios Tsounis, Sotiria Liori, Konstadinos Stamoulis, I. Ikonomidis, G. Filippatos, and J. Parissis. 2020. Telephone based survey in adults with congenital heart disease during COVID-19 pandemic. Cardiology Journal. [CrossRef] [PubMed]

Galea, Sandro, Raina Merchant, and Nicole Lurie. 2020. The mental health consequences of COVID-19 and physical distancing: The need for prevention and early intervention. JAMA Internal Medicine 180: 817-18. [CrossRef]

Gavalas, Vasilis. 2020. A threat to the humankind or much ado about nothing? Different perceptions of the coronavirus pandemic based on socio-demographic variables. Journal of Regional and Socio-Economic Issues 10: 21-39.

Georgakopoulos, Thodoris. 2020. How Greeks Live in the Pandemic. Available online: https://www.dianeosis.org/2020/04/poszoyn-oi-ellines-stin-pandimia/ (accessed on 25 February 2021).

Giannopoulou, Ioanna, and George Tsobanoglou. 2020. COVID-19 pandemic: Challenges and opportunities for the Greek health care system. Irish Journal of Psychological Medicine 37: 226-30. [CrossRef]

Glowacz, Fabienne, and Emilie Schmits. 2020. Psychological distress during the COVID-19 lockdown: The young adults most at risk. Psychiatry Research 293: 1-4. [CrossRef] [PubMed]

Independent SAGE. 2020. A Closer Look at Sweden's Response to COVID-19 The Independent SAGE Report 15. The Independent Scientific Advisory Group for Emergencies (SAGE). Available online: https:/ /www.independentsage.org/wp-content/uploads/ 2020/09/Sweden_case-study-v2.pdf (accessed on 11 March 2021).

Island Global Research. 2020. Wellbeing of Islanders Has Improved-More Than 50\% of People Are Now "Thriving". Available online: https: / / www.islandglobalresearch.com/Our-Reports (accessed on 9 March 2021).

Joshanloo, Mohsen, and Veljko Jovanović. 2020. The relationship between gender and life satisfaction: Analysis across demographic groups and global regions. Archives of Women's Mental Health 23: 331-38. [CrossRef]

Kivi, Marie, Isabelle Hansson, and P. Bjälkebring. 2021. Up and About: Older Adults' Well-being During the COVID-19 Pandemic in a Swedish Longitudinal Study. Journals of Gerontology: Psychological Sciences 76: e4-e9. [CrossRef]

Kutubaeva, Rosa. 2019. Analysis of life satisfaction of the elderly population on the example of Sweden, Austria and Germany. Population and Economics 3: 102-16. [CrossRef]

Marelli, Sara, Alessandra Castelnuovo, A. Somma, V. Castronovo, S. Mombelli, D. Bottoni, C. Leitner, A. Fossati, and L. Ferini-Strambi. 2020. Impact of COVID-19 lockdown on sleep quality in university students and administration staff. Journal of Neurology 1: 8. [CrossRef] [PubMed]

McCracken, Lance, F. Badinlou, M. Buhrman, and K. C. Brocki. 2020. Psychological impact of COVID-19 in the Swedish population: Depression, anxiety, and insomnia and their associations to risk and vulnerability factors. European Psychiatry 63. [CrossRef] [PubMed]

Moore, Dana, and J. Tarnai. 2002. Evaluating nonresponse error in mail surveys. In Survey Nonresponse. Edited by Robert Groves, Don Dillman, John Eltinge and Roderick Little. Hoboken: John Wiley and Sons, pp. 197-211. Available online: https:/ /scholar.google.com/scholar_lookup?title=SurveyNonresponseandpages=197-211andpublication_year=2002 andauthor=Moore\%2CD.L.andauthor=Tarnai\%2CJ (accessed on 1 February 2021). 
Moyser, Melissa. 2020. Gender Differences in Mental Health during the COVID-19 Pandemic. Available online: www.statcan.gc.ca (accessed on 21 February 2021).

National Public Health Organization. 2020. Epidemiological Surveillance Report of New Coronavirus Infection (COVID-19). Data as of 31 May 2020. Available online: https:/ / eody.gov.gr/wp-content/uploads/2020/05/covid-gr-daily-report-20200531.pdf (accessed on 21 March 2021).

OECD/European Commission. 2020. Cities in the World: A New Perspective on Urbanisation. Paris: OECD Publishing. [CrossRef]

Oishi, Shigehiro, Ed Diener, and Richard Lucas. 2018. Subjective Well-Being: The Science of Happiness and Life Satisfaction. In The Oxford Handbook of Positive Psychology, 3rd ed. Edited by Charles Snyder, Shane Lopez, Lisa Edwards and Susana Marques. Oxford: Oxford University Press. [CrossRef]

Parlapani, Eleni, Vasiliki Holeva, Panteleimon Voitsidis, A. Blekas, I. Gliatas, G. N. Porfyri, A. Golemis, K. Papadopoulou, A. Dimitriadou, A. F. Chatzigeorgiou, and et al. 2020a. Psychological and Behavioral Responses to the COVID-19 Pandemic in Greece. Frontiers in Psychiatry 11. [CrossRef]

Parlapani, Eleni, Vasiliki Holeva, Vasiliki Aliki Nikopoulou, K. Sereslis, M. Athanasiadou, A. Godosidis, T. Stephanou, and I. Diakogiannis. 2020b. Intolerance of Uncertainty and Loneliness in Older Adults During the COVID-19 Pandemic. Frontiers in Psychiatry 11. [CrossRef]

Peto, Julian, Alwan Nisreen, K. Godfrey, R. A. Burgesse, D. J. Hunter, E. Riboli, and P. Romeri. 2020. Universal weekly testing as the UK COVID-19 lockdown exit strategy. The Lancet 395: 1420-21. [CrossRef]

Pilcher, June, Douglas Ginter, and B. Sadowsky. 1997. Sleep quality versus sleep quantity: Relationships between sleep and measures of health, well-being and sleepiness in college students. Journal of Psychosomatic Research 42: 583-96. [CrossRef]

Polizzi, Craig, Steven Jay Lynn, and A. Perry. 2020. Stress and Coping in the Time of COVID-19: Pathways to Resilience and Recovery. Clinical Neuropsychiatry 17: 59-62.

Rambaree, Komalsingh, and Nessica Nässén. 2020. 'The Swedish Strategy' to COVID-19 Pandemic:Impact on Vulnerable and Marginalised Communities. The International Journal of Community and Social Development 2: 234-50. [CrossRef]

Routen, Ash, Natalie Darko, A. Willis, J. Miksza, and K. Khunti. 2020. The impact of Covid-19 and lockdown measures on self-reported life satisfaction and social relationships does not differ by ethnicity. Journal of Public Health. [CrossRef]

Sakka, Sofia, Vasiliki Aliki Nikopoulou, E. Bonti, P. Tatsiopoulou, P. Karamouzi, A. Giazkoulidou, V. Tsipropoulou, E. Parlapani, V. Holeva, and I. Diakogiannis. 2020. Assessing test anxiety and resilience among Greek adolescents during COVID-19 pandemic. Journal of Mind and Medical Sciences 7: 173-78. [CrossRef]

Singer, Eleanor, John Van Hoewyk, and M. P. Maher. 2000. Experiments with incentives in telephone surveys. Public Opinion Quarterly 64: 171-88. [CrossRef]

Smith, Ben, and Michelle Lim. 2020. How the COVID-19 pandemic is focusing attention on loneliness and social isolation. Public Health Research and Practice 30: e3022008. [CrossRef] [PubMed]

Smith, Mathew, Lesley Steinman, and E. A. Casey. 2020. Combatting social isolation among older adults in the time of physical distancing: The COVID-19 social connectivity paradox. Front Public Health. [CrossRef] [PubMed]

Stieger, Stefan. 2019. Facebook Usage and Life Satisfaction. Frontiers in Psychology 10: 2711. [CrossRef]

Torre, André. 2020. The interest of social distancing. Preprint. [CrossRef]

Tsipropoulou, Virginia, Vasiliki Aliki Nikopoulou, V. Holeva, Z. Nasika, I. Diakogiannis, S. Sakka, S. Kostikidou, C. Varvara, E. Spyridopoulou, and E. Parlapani. 2020. Psychometric Properties of the Greek Version of FCV-19S. International Journal of Mental Health and Addiction. [CrossRef]

Tubadji, Annie, Frederic Boy, and Don J. Webber. 2020. COVID-19: Narrative Economics, Public Policy and Mental Health I VOX, CEPR Policy Portal. In Covid Economics Vetted and Real-Time Papers. No. 20; Covid Economics, Vetted and Real-Time Papers. Vol. 20, Available online: https://voxeu.org/article/covid-19-narrative-economics-public-policy-and-mental-health (accessed on 15 March 2021).

UK Office for National Statistics. 2020. Personal Well-Being in the UK. Statistical Bulletin. Newport: UK Office for National Statistics.

Usher, Kim, Navjot Bhullar, and Debra Jackson. 2020. Life in the pandemic: Social isolation and mental health. Journal of Clinical Nursing. [CrossRef] [PubMed]

Vatavali, Fereniki, Zoi Gareiou, Fotini Kehagia, and Efthimios Zervas. 2020. Impact of COVID-19 on Urban Everyday Life in Greece. Perceptions, Experiences and Practices of the Active Population. Sustainability 12: 9410. [CrossRef]

White, Ross, and Catharina Van Der Boor. 2020. Impact of the COVID-19 pandemic and initial period of lockdown on the mental health and well-being of adults in the UK. BJPsych Open 6: e90. [CrossRef] [PubMed]

Wu, Cary, Zhilei Shi, Rima Wilkes, Jiaji Wu, Z. Gong, N. He, Z. Xiao, X. Zhang, W. Lai, D. Zhou, and et al. 2021. Chinese Citizen Satisfaction with Government Performance during COVID-19. Journal of Contemporary China, 1-15. [CrossRef]

Xuefei, Ren. 2020. Pandemic and Lockdown: A Territorial Approach to COVID-19 in China, Italy and the United States. Eurasian Geography and Economics. [CrossRef]

Zixin, Lambert, and Senhu Wang. 2020. Prevalence and predictors of general psychiatric disorders and loneliness during COVID-19 in the United Kingdom. Psychiatry Research 291: 113267. [CrossRef] 